\title{
Processo de expansão versus sustentabilidade urbana: reflexão sobre as alternativas de deslocamento na cidade de João Pessoa, PB
}

\author{
Expansion process versus urban sustainability: reflection about \\ displacement alternatives in the city of João Pessoa, PB
}

Luciana Andrade dos Passos ${ }^{[a]}$, Fabiana de Albuquerque Silveira ${ }^{[b]}$, Ana Luzia Lima Rodrigues Pita ${ }^{[c]}$,

Cybelle Frazão Costa Braga ${ }^{[d]}$, José Augusto Ribeiro da Silveira ${ }^{[e]}$

[a] Arquiteta e urbanista, Doutorado em Arquitetura e Urbanismo, Pós-Doutoranda em Arquitetura e Urbanismo (UFPB/ CAPES), João Pessoa, PB - Brasil, e-mail: lucianadospassos@hotmail.com

[b] Arquiteta e urbanista, Mestranda em Arquitetura e Urbanismo (PPGAU/UFPB), Manaíra, João Pessoa, PB - Brasil.

[c] Arquiteta e urbanista, Especialista em Arquitetura Hospitalar e Hoteleira, Mestranda em Arquitetura e Urbanismo (PPGAU/UFPB), João Pessoa, PB - Brasil.

[d] Engenheira civil, Doutorado em Recursos Naturais, Pós-Doutoranda em Arquitetura e Urbanismo (UFPB/CAPES), João Pessoa, PB - Brasil.

[e] Arquiteto e urbanista, Doutorado em Desenvolvimento urbano (UFPE), professor do Departamento de Arquitetura do Centro de Tecnologia da UFPB, Cabedelo, PB - Brasil.

\section{Resumo}

Este artigo analisa questões da expansão de cidades de porte médio, como João Pessoa, capital do Estado da Paraíba, com o objetivo de verificar a atuação de diferentes segmentos da sociedade civil, da iniciativa privada e do setor público e suas contribuições para a implantação de um modelo espraiado de crescimento. Esse estudo compara o modelo automobilístico-rodoviário aos preceitos defendidos pela linha de pensamento em oposição, ou seja, a "sustentabilidade urbana". Para tanto, faz-se referência aos estudos já desenvolvidos sobre a evolução urbana de João Pessoa, relacionando as intervenções urbanas com os atores envolvidos nas ações de melhorias no setor de transportes. Por fim, os planos e projetos contemporâneos propostos para o transporte coletivo são analisados sob a ótica dos preceitos da sustentabilidade urbana, enfatizando-se a necessidade de diálogo entre os diferentes atores sociais para a implantação de alternativas de deslocamento compatíveis com complexidades e especificidades históricas, culturais, sociais, políticas e econômicas locais.

Palavras-chave: Espraiamento urbano. Sustentabilidade urbana. Atores sociais.

\section{Abstract}

This paper examines issues of expansion of mid-sized cities, such as João Pessoa, capital of the State of Paraiba, in order to verify the performance of different segments of civil society, of private initiative and public sector and its contributions to the deployment of a sprawling growth model. This study compares the car-road model to the precepts espoused by an opposed line of thought, the "urban sustainability". For this purpose, 
reference is made to the studies already undertaken on the urban evolution of João Pessoa, urban interventions relating to the actors involved with the improvements in the transportation sector. Finally, the proposed plans and contemporary designs for public transport are analyzed from the perspective of the principles of urban sustainability, emphasizing the need for dialogue between different social actors to deployment of alternative shift compatible with the historical, cultural, social, political and economic location's complexity and specificity.

Keywords: Urban sprawl. Urban sustainability. Social actors.

\section{Introdução}

Em inúmeras cidades pode-se observar um processo de expansão, no qual a estrutura física é irradiada para todos os lados. A este processo denomina-se urban sprawl ou espraiamento urbano, definido por Jakob (2002) como o fenômeno de expansão urbana que segue um princípio de "organização" desequilibrada e espraiada. Este artigo analisa questões da expansão de cidades de porte médio, a exemplo de João Pessoa, capital do Estado da Paraíba, com o objetivo de verificar a atuação de diferentes segmentos da sociedade civil, da iniciativa privada e do setor público e suas contribuições para a implantação de um modelo espraiado de crescimento.

Este estudo compara o modelo automobilístico-rodoviário aos preceitos defendidos pela linha de pensamento em oposição: a "sustentabilidade urbana". Para tanto, foi realizado o levantamento bibliográfico dos principais estudos referentes à evolução urbana de João Pessoa (COUTINHO, 2004; OLIVEIRA, 2006), relacionando as intervenções urbanas marcantes na malha urbana com os atores envolvidos nas ações de melhorias no setor de transportes.

A primeira parte do texto enfoca os planos e projetos contemporâneos concebidos, ao longo da história, para o transporte coletivo de João Pessoa, analisando-os sob a ótica dos preceitos da sustentabilidade urbana (SILVEIRA; RIBEIRO, 2006). A segunda parte expõe algumas críticas referentes ao tema de transporte na capital, pesquisadas em jornais locais, como subsídio para estimular algumas reflexões.

\section{Conceituação e contextualização do tema}

0 espraiamento urbano corresponde ao crescimento exagerado da cidade a partir de eixos principais de acesso e de práticas, com a produção de subúrbios, condomínios horizontais de luxo e conjuntos habitacionais populares localizados nas franjas ou bordas urbanas distantes do centro principal e da mancha consolidada da cidade. Esse conceito surgiu na década de 1960 a partir dos estudos realizados na cidade americana de Los Angeles e, desde então, o espraiamento está sendo estudado em inúmeras cidades no mundo.

A relação biunívoca entre percursos e evolução urbana - no que se refere à morfologia, à radialidade do sistema de acessos principais e à segregação - afeta a estrutura física, o meio ambiente e a qualidade de vida das pessoas, dada a contínua fragmentação e o espraiamento urbano a partir dos quais a cidade nunca "cresce para dentro". Contudo, efeitos nocivos são verificados a partir desse processo de expansão urbana, com danos ao meio ambiente natural periurbano, desvalorização e deterioração da área central da cidade, prejuízos ao consumo espacial, temporal, energético e material, e aumento das desigualdades sociais e espaciais, tornando os mais pobres ainda mais distantes das melhores oportunidades urbanas (SILVEIRA; RIBEIRO, 2006).

Tal como acontece com todos os produtos do trabalho, o capitalismo faz o possível para transformar o espaço urbano produzido em mercadoria. Estimulados por interesses imobiliários e novas localizações, as elites urbanas no Brasil estão constantemente produzindo novos espaços e deixando outros para trás. A classe de maior poder aquisitivo foi ocupando as áreas que lhes eram mais convenientes e, consequentemente, gerando formas diferenciadas de apropriação do espaço urbano. Logo, originou-se uma dinâmica social caracterizada por uma segregação imposta às classes menos favorecidas. Para elas, sobravam as periferias da cidade, aumentando ainda mais a expansão urbana (VILLAÇA, 2001). 
O tecido intraurbano de uma cidade se desenvolve diferenciadamente no uso e na ocupação do solo, sendo determinado, em grande medida, pela dinâmica imobiliária. Esta dinâmica envolve agentes sociais que fazem e refazem a cidade. A complexidade da ação desses agentes inclui práticas que conduzem a um processo contínuo de reorganização espacial que ocorre por meio da incorporação de novas áreas ao espaço urbano, da densificação do uso do solo, da deterioração de algumas áreas, da implantação de infraestrutura diferenciada e da renovação urbana (CORRÊA, 1993).

Os mecanismos utilizados na formação do preço do solo no espaço intraurbano foram, e continuam sendo, parte de um processo responsável pelo alto índice de segregação social e fisicoterritorial. Todas as esferas sociais são atingidas pela especulação imobiliária. Neste processo de transformação, expansão desordenada e de segregação socioespacial, a cidade perde em qualidade de vida para todos os seus habitantes.

A acessibilidade, a morfologia, a localização e a lógica de evolução urbana são elementos físico-territoriais fundamentais na questão do valor do solo, com implicações no desenvolvimento socioeconômico.

Ojima (2008) destaca, ainda, que a expansão significativa da cidade implica em maiores distâncias entre os núcleos de desenvolvimento urbano de uma mesma dinâmica regional. E, consequentemente, um dos principais problemas é a questão do deslocamento e o uso intensivo do transporte automotivo, em especial, o individual.

A estrutura urbana gerada no tipo de sistema altamente segregado é dispersa, com grandes perdas para o funcionamento dos sistemas de circulação, distribuição de água, energia elétrica, com dificuldades na oferta de serviços públicos, como os transportes coletivos.

Os processos de desenvolvimento econômico e urbano criaram e consolidaram novas classes médias, as quais tiveram mudanças no modo de vida e de consumo, e como consequência, essas classes passaram a optar pelo transporte particular. Com o incremento da indústria automobilística brasileira, a partir do final dos anos cinquenta, o número de automóveis na cidade começou a crescer rapidamente, atingindo, na década de 80, 1,8 milhão (VASCONCELLOS, 2001).
O elevado número de veículos em circulação nos centros urbanos tem acarretado problemas ao trânsito, em vista da dificuldade crescente de mobilidade de bens e pessoas por meio do sistema viário. Em decorrência desse problema, estão presentes os acidentes de trânsito, a poluição e os congestionamentos, e os transportes públicos veem o seu espaço cada vez mais reduzido e a sua operação dificultada, com efeitos sobre a qualidade do serviço.

Além disso, segundo Campos Filho (2001 apud FREIRE, 2008), as soluções radioconcêntricas dominantes até a década de 1950 - receberam impacto a partir do aumento do uso dos automóveis, o qual requer um espaço viário cada vez maior que logo se torna congestionado comprometendo a eficiência dos percursos. Com a ocorrência de congestionamento de tráfego, os tempos de viagem ficam cada vez maiores e a solução (frequente) aplicada pelo gestor público é aumentar a frota para manter o mesmo número de viagens, fato que não diminui o tempo do trajeto, mas contribui gradativamente para a degradação do transporte público e para a fuga de seus usuários para outros tipos de transporte. A Figura 1 destaca a interferência cíclica entre os elementos da expansão urbana versus o transporte.

O automóvel privado também parece ser psicologicamente importante à população, considerando que fatores como o prazer, a privacidade, o controle pessoal e a representatividade, contribuem para a

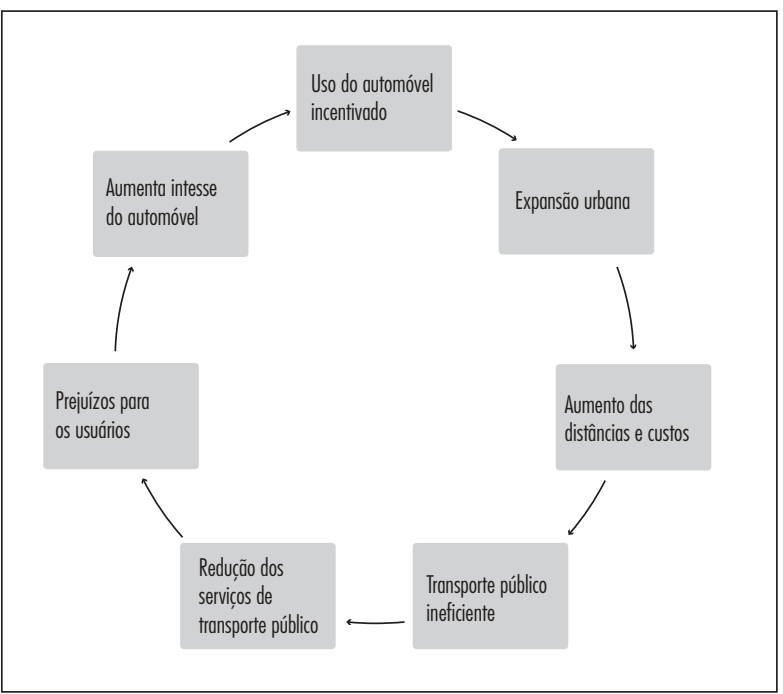

Figura 1 - Ciclo de problemas: expansão urbana e transporte Fonte: Adaptado de ANTP, 1997. 
preferência por este tipo de locomoção, acarretando uma resistência à coletivização do transporte já que as desvantagens percebidas com o meio de transporte privado parecem ser baixas (NIJKAMP; RIENSTRA, 1995).

$\mathrm{Na}$ Holanda, foi realizada uma pesquisa referente às medidas políticas e às potencialidades desejadas para o incentivo de novos meios de transportes. A pontuação mais alta (esperada) foi encontrada no aumento das taxas de estacionamento, o que podem tornar o uso de carros particulares menos atraentes. A segunda pontuação mais alta foi dada para a redução do número de vagas de estacionamento. A pontuação dos especialistas sobre o uso esperado de todos os modos convencionais de transporte (exceto para o trem) varia. A maior pontuação foi atribuída ao metrô, que deverá ser introduzido em grande escala. Quanto aos outros meios de transporte, carro e modos lentos (ciclismo e pedestrianismo) apresentaram as pontuações mais próximas, enquanto o ônibus e o bonde obtiveram pontuação um pouco menor (NIJKAMP; RIENSTRA, 1995).

Para Campos Filho (2003), o adensamento de atividades ao longo de linhas de transporte coletivo ou de vias de grande capacidade de tráfego poderia ser adotado com o objetivo de incentivar o uso do transporte público. Segundo o autor, o planejamento do uso do solo, planejamento territorial ou físico são importantes medidas de política de intervenção para lidar com questões de transporte, pois os locais existentes (residências, indústrias, serviços públicos e áreas de recreação) determinam as necessidades de transporte em curto prazo.

Assim, também sob a ótica da sustentabilidade urbana (uma forma de pensamento sistêmico relacionado com a continuidade dos aspectos sociais, econômicos, culturais e ambientais da sociedade humana), o espraiamento urbano apresenta efeitos nocivos decorrentes da expansão descontrolada ou desorganizada do espaço urbano. À medida que a cidade cresce desmesuradamente, novos e vultosos investimentos tornam-se necessários e a estrutura urbana torna-se pouco sistêmica, setorizada e espraiada, intensificando a segregação e gerando obstáculos à inclusão social.

Para Ribeiro e Silveira (2009), a adoção do modelo espraiado de expansão equivale ao ciclo linear "obter > utilizar > descartar". Em oposição a esse fenômeno de espraiamento, considerado antiecológico, estaria o entendimento de que a compactação e a requalificação de centros urbanos se enquadrariam no modelo circular, incorporando o princípio dos "3 R": "reduzir o consumo do espaço natural $>$ restaurar ou requalificar $>$ reutilizar". Com isso, do ponto de vista ambiental, parte dos espaços naturais e ecossistemas continuariam ativos, elevariam a qualidade de vida urbana e, no que se refere aos espaços de produção rural, seria possível preservar áreas produtivas evitando-se, por exemplo, as migrações populacionais.

Nesse sentido, a linha de pensamento da sustentabilidade urbana defende a compacidade urbana (compact cities) que também viabilizaria o pedestrianismo, o ciclismo e o transporte coletivo. Vale salientar que a própria "solução" da compacidade do urbano também recebe críticas, sendo considerada como antiecológica, uma vez que conduziria ao congestionamento e à concentração de poluentes argumento contestado pelos defensores da sustentabilidade urbana.

Por conseguinte, na tentativa de um ordenamento territorial, idealiza-se a "cidade compacta", com foco na valorização de formas de circulação mais benéficas e ecológicas, como o pedestrianismo, o ciclismo, o uso de transportes públicos, a redução da utilização do automóvel e do nível de mobilidade, minimizando, dessa forma, as externalidades ambientais e o congestionamento. Além disso, é importante ressaltar os aspectos de gestão pública e sua relação direta com a sustentabilidade. Nas palavras de Campreciós (2008, p. 28), a participação dos atores urbanos é fundamental para a concepção de um modelo de cidade sustentável:

A cidade não é propriedade de nenhum dos dois componentes (público ou privado), é patrimônio de ambos e deve ser concebido pelas duas partes como um capital de interesse comum. Falar de cidade e de sustentabilidade obriga a refletir sobre os atores urbanos e sua implicação nos modelos de cidade sustentável. A cidade sustentável não é feita exclusivamente pela administração pública, deve ser feita desde o princípio pelo consenso e participação de todos os atores.

0 autor defende, ainda, que "a governabilidade da sustentabilidade requer práticas compartilhadas com os interesses dos distintos grupos que 
configuram a cidade e de objetivos gerais que sejam referência para cada um deles" (CAMPRECIÓS, 2008, p. 28).

Com base no referencial teórico exposto, abarcando os temas de expansão, espraiamento, atores implicados e sustentabilidade urbana, apresenta-se a seguir a evolução da cidade de João Pessoa, sob o enfoque das alternativas de deslocamento adotadas ao longo da história.

\section{Evolução da cidade de João Pessoa e suas implicações no tecido intraurbano}

João Pessoa, em 1585, na época denominada de Nossa Senhora das Neves, surgiu às margens do Rio Sanhauá (braço do Rio Paraíba), já com título de cidade sob "expressa determinação do rei" (AGUIAR, 2002, p. 19) diante das explorações na capitania realizadas pelos franceses aliados aos índios potiguares. Com parcos recursos destinados fundação da cidade, Nossa Senhora das Neves obteve seus melhoramentos (estradas e pontes) a partir da iniciativa privada (GONÇALVES et al., 1999).

Contudo, mesmo durante a dominação holandesa, de 1634 a 1654 , o traçado urbano apresentou poucas modificações permanecendo seu traçado original contendo vários terrenos vazios. Quanto aos acessos, é possível observar no acervo iconográfico (Figura 2) as estradas que interligavam o núcleo de fundação da cidade ao interior da Capitania da

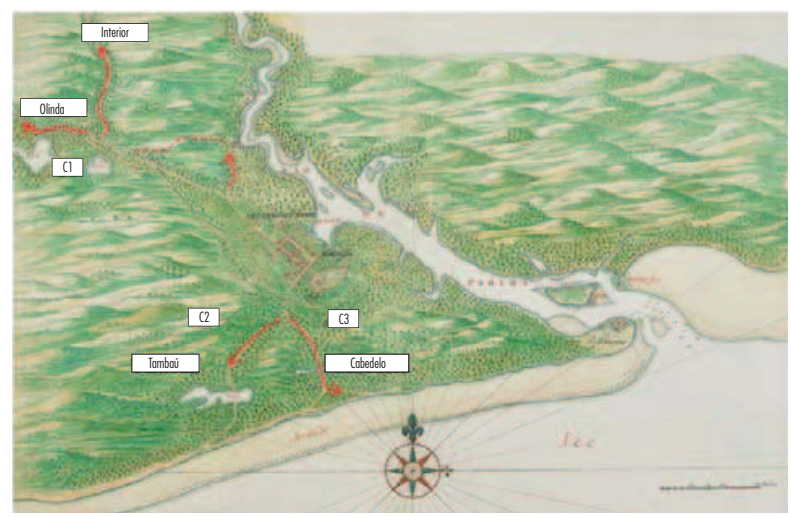

Figura 2 - Iconografia, época do domínio holandês, 1647 Fonte: GOULART FILHO, 2000 apud OLIVEIRA, 2006.
Parahyba ou à Capitania de Pernambuco (C1), à orla marítima de Tambaú (C2) e à planície de Cabedelo (C3) (OLIVEIRA, 2006).

0 transporte de produtos agrícolas foi determinante na evolução espacial da cidade. Durante a ocupação holandesa houve um fortalecimento da produção de cana-de-açúcar nos engenhos da região. Contudo, em função da escassez e da imprecisão dos dados até o século XIX (OLIVEIRA, 2006), serão citados neste texto apenas os acontecimentos históricos da evolução urbana a partir do século XIX.

Com o incremento advindo do comércio agrícola em 1855, a cidade, com 20.099 habitantes e uma área de $1,86 \mathrm{~km}^{2}$, apresentava densidade demográfica de 108,14 hab./ha (OLIVEIRA, 2006). 0 carro de boi era utilizado como forma de deslocamento para as áreas distantes do perímetro urbano (ALMEIDA, 1982 apud OLIVEIRA, 2006).

Com estrutura de pequeno porte, as poucas obras públicas construídas na capital eram criticadas pelos seus governantes. Entre 1855 e 1857, Antonio da Costa Pinto e Silva, presidente da província da Paraíba, enfatizou que recursos significativos foram investidos em obras públicas de baixa qualidade. No governo subsequente, o tenente-coronel Beaurepaire Rohan também criticou a falta de planejamento e de normas de controle urbanístico na província (OLIVEIRA, 2006).

Posteriormente, legisladores aprovaram leis de caráter urbanístico. No dia 30 de setembro de 1859, foi instituída a Lei n. 26, estabelecendo normas para edificações e autorizando a aberturas de novas ruas (ALMEIDA, 1982 apud OLIVEIRA 2006). No dia 7 de setembro de 1883, foi inaugurada a primeira linha de trem, estendendo-se inicialmente até a localidade denominada Mulungú, sendo ampliada ${ }^{1}$ até o porto de Cabedelo em 25 de março de 1889, ano em que a cidade possuía $2,14 \mathrm{~km}^{2}$ e uma população reduzida em virtude da subtração do município de Santa Rita do território da capital, e densidade de 87 hab./ha.

Ainda no fim do século XIX, em 6 de junho de 1896, foram implantados, no núcleo inicial da capital, os trilhos destinados ao serviço de transporte coletivo de bondes movidos à tração animal. A companhia empreendedora, a Ferro-Carril Parahybana,

\footnotetext{
${ }^{1}$ Interligação ainda em uso pelo transporte ferroviário atual.
} 
prolongou progressivamente o percurso do bonde, interligando o núcleo inicial à orla marítima (Ferrovia Tambaú) no ano de 1907, com linha de transporte público movida por locomotiva a vapor (OLIVEIRA, 2006).

Em três décadas, de 1890 a 1910, a área urbana da capital passou de $2,14 \mathrm{~km}^{2}$ para $5,84 \mathrm{~km}^{2}$, caracterizando-se pela concentração urbana em um pequeno território, atingindo a densidade populacional de 104,69 hab./ha (OLIVEIRA, 2006). A cidade apresentava ainda poucos acessos direcionados a outros núcleos urbanos (à Cabedelo, ao interior da Capitania ou à Capitania vizinha) e à orla marítima.

No início do século XX, os governantes realizaram sucessivas intervenções no traçado urbano. Entre 1908 e 1912, o governo do médico sanitarista João Lopes Machado, influenciado pelas reformas de Pereira Passos e Oswaldo Cruz no Rio de Janeiro, implantou obras de abastecimento de água, iluminação pública, serviços de saúde pública, pavimentação de ruas e aberturas de vias.

A construção da Avenida João Machado simbolizou o início de uma nova fase da cidade, uma vez que a abertura dessa via foi seguida pelo surgimento de novos loteamentos, remoção das choupanas da população residente (e deslocamento desta para áreas vizinhas menos valorizadas), e construção de palacetes de famílias abastadas nas imediações da nova avenida (COUTINHO, 2004).

A partir de 19 de fevereiro de 1914, durante o governo de Castro Pinto, os bondes de tração animal foram substituídos pelos bondes elétricos. Ainda nesse governo, foi elaborado o primeiro projeto urbanístico direcionado ao saneamento e embelezamento da cidade, concebido por Saturnino de Brito, porém não foi executado na época em função da falta de recursos (OLIVEIRA, 2006).

No Governo de Camilo de Holanda (1916-1920), foram realizadas obras vultuosas, como alargamentos de ruas existentes e aberturas de vias, como a Avenida Maximiano de Figueiredo (OLIVEIRA, 2006). Em 1919, foi aprovada Lei Orçamentária Federal destinada à realização de prospecções para instalação de novo porto da cidade na Praia de Tambaú (COUTINHO, 2004), embora posteriormente tenha sido verificada a impossibilidade da localização desse empreendimento na área.

Apenas entre 1920 e 1924, na gestão do Prefeito Walfredo Guedes Pereira e do Presidente do Estado
Solon de Lucena, foi retomada a proposta de esgotamento sanitário de Saturnino de Brito, com início das obras de drenagem pluvial e urbanização da Lagoa dos Irerês, possibilitando inclusive a expansão urbana para o setor leste. Ainda nessa época, ocorreram demolições (residências e igrejas), além de reestruturações viárias nos pontos de principais fluxos de pessoas, bondes e veículos (Ponto de Cem Réis) (COUTINHO, 2004).

É importante registrar que, de acordo com Oliveira (2006), as faíscas e as fumaças das caldeiras do trem a vapor incomodavam os usuários, de forma que a solução adotada em 1922 foi adaptar o caminhão Ford (motor a gasolina) com rodas de ferro sobre os trilhos contendo uma carroceria com capacidade para 20 passageiros. E ainda segundo o autor, em 1929, a Empresa Auto-Viação, fundada por Oswaldo Pessoa, assinou o primeiro contrato de concessão de serviço público para a utilização do ônibus como transporte coletivo urbano. Paralelamente, em 1932, o serviço de bondes tornava-se cada vez mais precário, apresentando veículos desgastados e em péssimo estado de conservação, movidos com suprimento deficiente de energia elétrica.

0 interventor Atenor Navarro, sob a coordenação do engenheiro Ítalo Joffily, no período de 1933 a 1936, (re)estruturou a Avenida Epitácio Pessoa (segmento de reta final da Ferrovia Tambaú, na Figura 3), fato que contribuiu para intensificar a ocupação da orla marítima. Ainda nessa época, o urbanista Nestor de Figueiredo, a partir do resultado das intervenções urbanas do prefeito Walfredo Guedes Pereira, apresentou um anteprojeto de remodelação e extensão urbanas. Dentre outras propostas, o Parque Solon de Lucena (antiga Lagoa dos Irerês) novamente foi considerado ponto focal para irradiar a expansão da cidade (OLIVEIRA, 2006).

No governo de Argemiro de Figueiredo (19351940), as linhas de bonde foram ampliadas ou duplicadas, novos veículos foram adquiridos e trilhos foram substituídos. Na década de 1930, a cidade abrigava uma frota de 18 automóveis de passageiros, 14 auto-ônibus e cinco empresas de transportes coletivos (OLIVEIRA, 2006).

Em 1940, a Avenida Epitácio Pessoa recebeu, pelo interventor do Estado, Rui Carneiro, a implantação da linha de bondes elétricos e as primeiras linhas de ônibus ("sopas") com destino à Praia de 


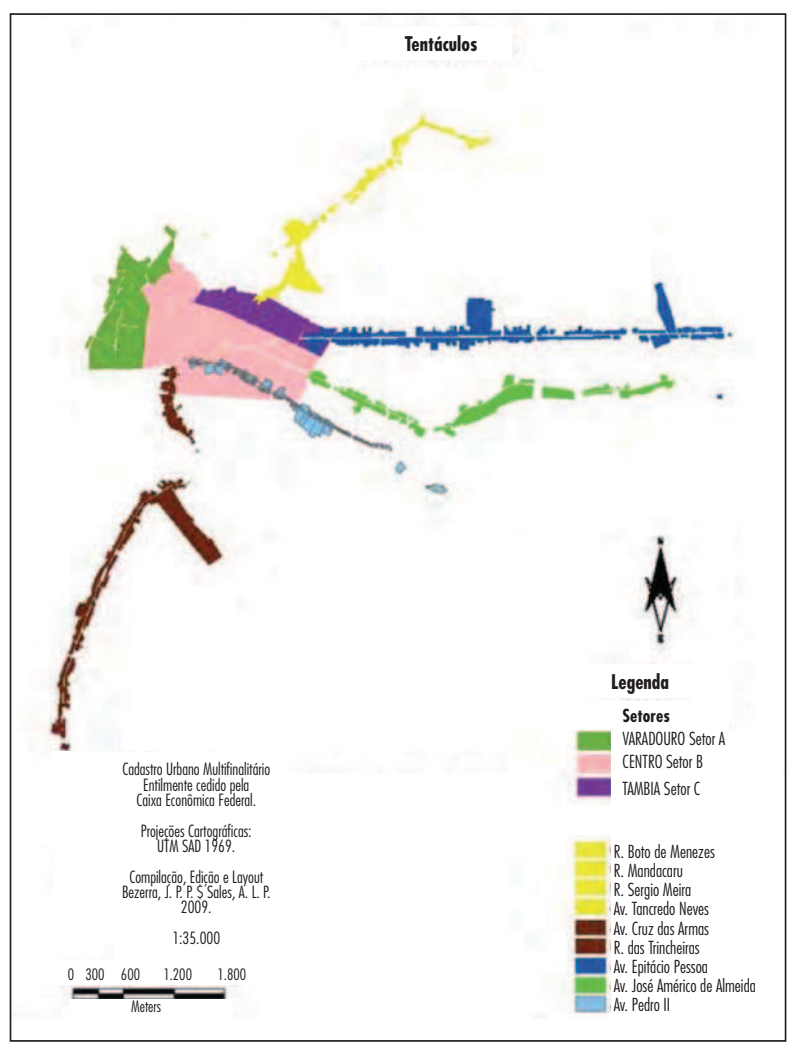

Figura 3 - Centro e principais corredores da cidade, tentáculos Fonte: Cadastro Urbano Multifinalitário, cedido pela Caixa Econômica Federal. Compilação, edição e layoư de BEZERRA; SALES, 2009 apud SALES, 2009.

Tambaú, possibilitando, com isso, o deslocamento do centro às praias. Ainda, novos loteamentos urbanos foram aprovados em 11 de outubro de 1948, no primeiro Código de Posturas e na primeira Lei Orgânica de João Pessoa, e novos bairros surgiram na parte sul da cidade, estimulados pela implantação da Cidade Universitária no governo de José Américo de Almeida, na década de 1950. Nesse período, foram construídos conjuntos habitacionais localizados em áreas afastadas do centro da cidade, como os bairros de Expedicionários e Jaguaribe, bem como nos bairros do Centro, Torre e Tambiá (COUTINHO, 2004).

Em 1950, no governo de José Américo (19511956), a Avenida Epitácio Pessoa foi pavimentada e o bonde paulatinamente foi "perdendo prestígio" e a "primazia" passava para os ônibus e a lotação (marinetes) (MELLO, 1955 apud OLIVEIRA, 2006). As duas últimas linhas de bonde, a Linha do Comércio e a Linha Tambaú, deixaram de operar em 1960, no período do governador Pedro Gondim. 0 prolongamento da Avenida Dom Pedro II e a abertura da Avenida Cruz das Armas possibilitou o desenvolvimento da cidade na direção sul e sudeste (FERRAZ; DUAYER, 1985). Observou, ainda, a valorização imobiliária no entorno desse eixo viário, sobretudo a partir da construção de residências de alto luxo.

0 processo de expansão de João Pessoa continuou na direção leste. A área litorânea continuou a receber investimentos com a construção de grandes conjuntos habitacionais, tanto no governo de Domingos Mendonça (1963-1966), quando o município recebeu o controle do sistema de transporte coletivo por ônibus com a pavimentação da antiga Avenida Atlântica - posteriormente denominada de Avenida Ruy Carneiro - quanto no governo de João Agripino (1966-1971), com a instalação do Hotel Tambaú, marco da evolução do bairro de Tambaú em razão dos melhoramentos nos serviços de infraestrutura e equipamentos urbanos, e início do processo de verticalização da orla marítima. Surgiu, a partir de então, a incorporação urbana das faixas litorâneas dos bairros de Cabo Branco e Tambaú pelas camadas de mais alta renda (COUTINHO, 2004).

Em 1974, a Prefeitura Municipal de João Pessoa elaborou o Plano de Desenvolvimento Urbano (PDU), criando o Código de Urbanismo. Este estabeleceu, dentre outras diretrizes, a expansão da cidade em direção à zona sul, à cidade universitária e à orla marítima, além da descentralização para os núcleos dos bairros, a recuperação da cidade baixa por meio da implantação de grandes terminais, incluindo o terminal de passageiros rodoviários, e a aprovação de loteamentos vinculada à implantação de infraestrutura básica pelo loteador (OLIVEIRA, 2006).

É importante ressaltar que nos anos de 1977 e 1978 , foram elaboradas duas propostas ${ }^{2}$ para o plano integrado de transporte (Figura 4), concebido por Jaime Lerner, contratado pelo Prefeito Hermano Almeida. O plano, apesar de não ter sido executado, influenciou os planos de transportes posteriores (OLIVEIRA, 2006).

Dentre diversas diretrizes concebidas no Plano de 1977, podem ser citadas, ainda de acordo com o autor, a indicação das avenidas Cruz das Armas e

2 A Coordenadoria de Geral de Planejamento da Prefeitura Municipal exigiu uma revisão do plano de 1977. 


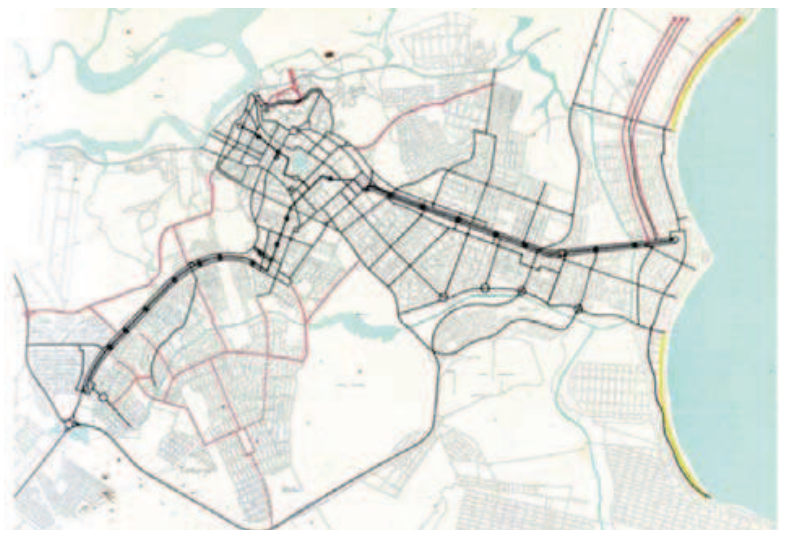

Figura 4 - Intervenções físicas, segunda proposta de Jaime Lerner para 0 Plano Integrado de Transporte de João Pessoa, 1978

Fonte: LERNER, 1978 apud OLIVEIRA, 2006.

Epitácio Pessoa/Ruy Carneiro como principais eixos naturais de crescimento da cidade. A proposta então seria reunir a ossatura viária, o uso do solo e o transporte coletivo sobre esses eixos. Na época, dois novos corredores viários estavam em formação: a Av. Dom Pedro II, começando no Centro e se estendendo até a Cidade Universitária na zona sul; e a Av. Alberto de Brito, no bairro de Jaguaribe até o bairro do Cristo Redentor, passando pela CEASA até chegar ao Estádio José Américo de Almeida. No Plano de 1978, nos eixos estruturais, haveria uma separação ou uma priorização de uma das faixas para o ônibus. Vale ressaltar ainda que, entre 1972 e 1983, a área urbana dobrou de dimensão e a população cresceu 78,32\%, espalhando-se pelas áreas pobres da cidade (OLIVEIRA, 2006).

Contudo, no governo de Wilson Braga (19831986), de acordo com Coutinho (2004), as ações da Fundação Social de Apoio ao Trabalho (FUNSAT) construíram conjuntos (mal planejados) nos vales e encostas, com grau mínimo de infraestrutura e precárias condições de moradia. Ainda segundo o autor: "o Rio Jaguaribe passou a abrigar [...] em vários pontos das suas margens, populações inteiras que convivem com a alta densidade, falta de saneamento básico, limpeza urbana, falta de lazer, além de doenças causadas pela poluição e pelo assoreamento" (COUTINHO, 2004, p. 96).

Em 1983, a Empresa Brasileira de Planejamento de Transportes (GEIPOT), contratada pela prefeitura, realizou o Estudo de Transportes Urbanos de João Pessoa, reunindo-o no Relatório para
Implantação Imediata (PAITT). Como medidas para a melhoria da circulação na área central, apontou a ampliação das áreas de pedestres nas principais vias comerciais, a racionalização dos estacionamentos e o disciplinamento das operações de carga e descarga. Essas medidas foram fundamentadas nas premissas de redução do tempo de espera de viagem, bem como do tempo necessário para o deslocamento a pé, minimização do número de transferências e lotação máxima do veículo de 80 passageiros. Direcionado à área central, propunha pistas e faixas exclusivas de ônibus (dentre outras ações) e áreas de pedestres nas principais vias comerciais e ciclovias interligando o Centro ao Bairro da Torre.

Já as Recomendações para Implantação a Médio Prazo (Transcol) foram destinadas às regiões circunvizinhas de João Pessoa, sugerindo uma configuração radial para a maioria das linhas de ônibus, complementada por linhas transversais e mais uma diametral, além da integração modal entre ônibus e trem de subúrbio, do controle do estacionamento de veículos privados nos corredores urbanos para segurança e fluidez no tráfego, e do estudo de ciclovias (OLIVEIRA, 2006).

Registra-se, ainda, que o período entre as décadas de 1970 e 1990 correspondeu ao momento de maior intensidade do sprawl urbano (Figura 4), de diminuição da densidade populacional para índices abaixo do ideal, contínuo processo de formação de vazios urbanos e de aumento da ação especulativa (RIBEIRO et al., 2007).

O Plano Diretor de João Pessoa de 1992/1994 priorizou o transporte público coletivo em detrimento do transporte privado e a circulação do transporte coletivo na rede viária principal, sobretudo nos corredores de grande capacidade e na zona do Centro Principal. Além disso, estabeleceu como uma das diretrizes a definição de procedimentos para avaliação dos impactos causados por polos geradores de tráfego e na aprovação desse tipo de empreendimento. Contudo, algumas das problemáticas do transporte urbano de João Pessoa referem-se às distâncias dos bairros em relação Centro, além do número de vazios urbanos (Figura 5).

De acordo com Silveira et al. (2008), em João Pessoa o processo desordenado de expansão intraurbana, os setores socialmente mais seletivizados e o crescimento da importância do circuito superior da economia, da prestação de serviços mais 
sofisticados e do comércio geraram uma estrutura mais assimétrica, na qual a cidade organiza-se em fatias socioespaciais, resultando em efeitos nocivos à sustentabilidade e à qualidade de vida. Podem ser citados como exemplos desses efeitos danosos principais do modelo de expansão desordenado: (i) espraiamento urbano com impactos sobre o meio ambiente natural periurbano; (ii) desvalorização e deterioração da área central tradicional; (iii) reflexo do consumo espacial, temporal, energético e material sobre os provimentos urbanos e a qualidade de vida da população; e (iv) diferenciação da macroacessibilidade, aumentando as desigualdades nos espaços intraurbanos (SILVEIRA et al., 2008).

Além disso, em duas zonas da cidade de João Pessoa, a ocupação e o uso do solo estão interferindo na eficiência do transporte urbano. Na zona sudeste, a ocupação ocorre predominantemente de forma horizontal e se distancia cada vez mais do centro da cidade. Já na zona leste, em virtude do limite imposto pelo oceano, ocorre um adensamento caracterizado pela verticalização das habitações. Logo, como este adensamento é fruto da procura da classe abastada por áreas mais valorizadas, a capacidade de tráfego das vias de acesso está cada vez mais comprometida pelo uso excessivo do automóvel (FREIRE, 2008).

$\mathrm{Na}$ zona sudeste, que tem como eixo principal o corredor da Avenida Dom Pedro II, a cada dia novos loteamentos e conjuntos habitacionais vão se formando. Esse setor da cidade abriga predominantemente uma população de baixa renda que depende do transporte público para se deslocar no seu dia a dia. No entanto, a falta de qualidade do transporte acaba comprometendo a mobilidade na área (FREIRE, 2008). 0 núcleo tradicional da cidade foi perdendo a sua diversidade nos usos e funções e, consequentemente, veio a passar por um processo de deterioração dos seus imóveis, como também de descaracterização por usos impróprios, como oficinas mecânicas por exemplo. Esse processo de descentralização se intensificou nas últimas décadas (Figura 6).

A expansão de João Pessoa ocorreu de forma semirradioconcêntrica, acentuando territórios periféricos, setores de círculo e a segregação das classes sociais, de acordo com o esquema estrutural urbano de Hoyt, no qual a segregação espacial assume um padrão de desenvolvimento em setores a partir do

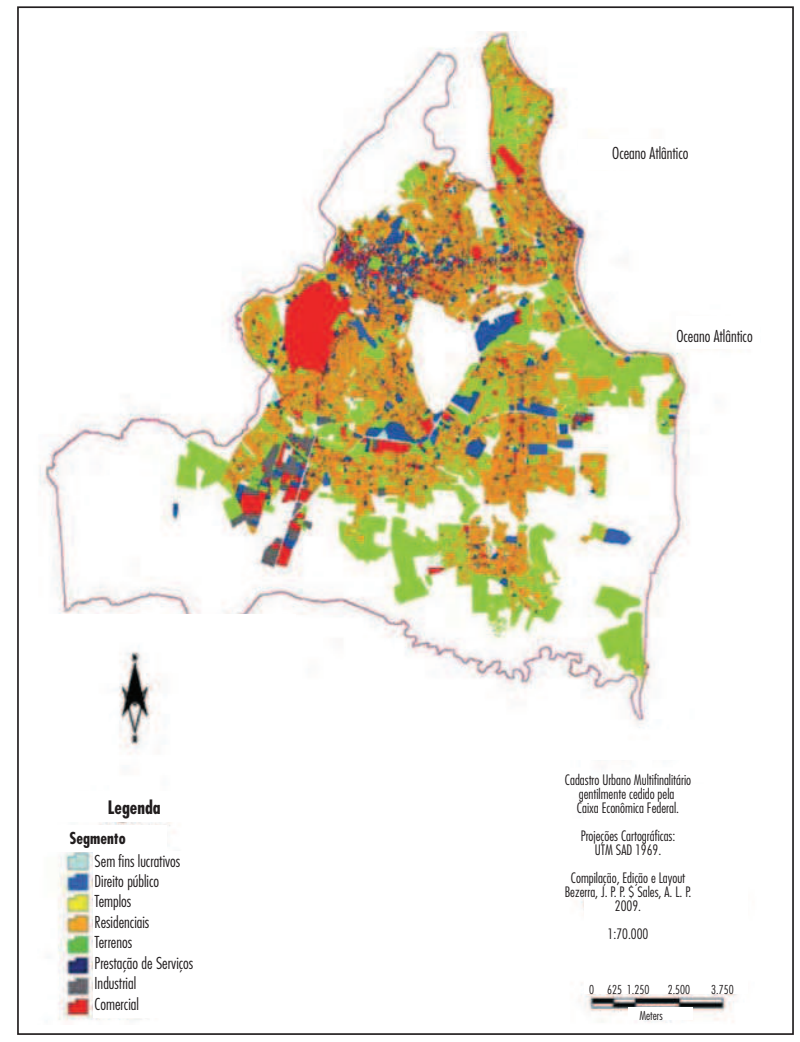

Figura 5 - Dispersão do comércio e de serviços em João Pessoa Fonte: Cadastro Urbano Multifinalitário, cedido pela Caixa Econômica Federal. Compilação, edição e layout de BEZERRA; SALES, 2009 apud SALES, 2009.

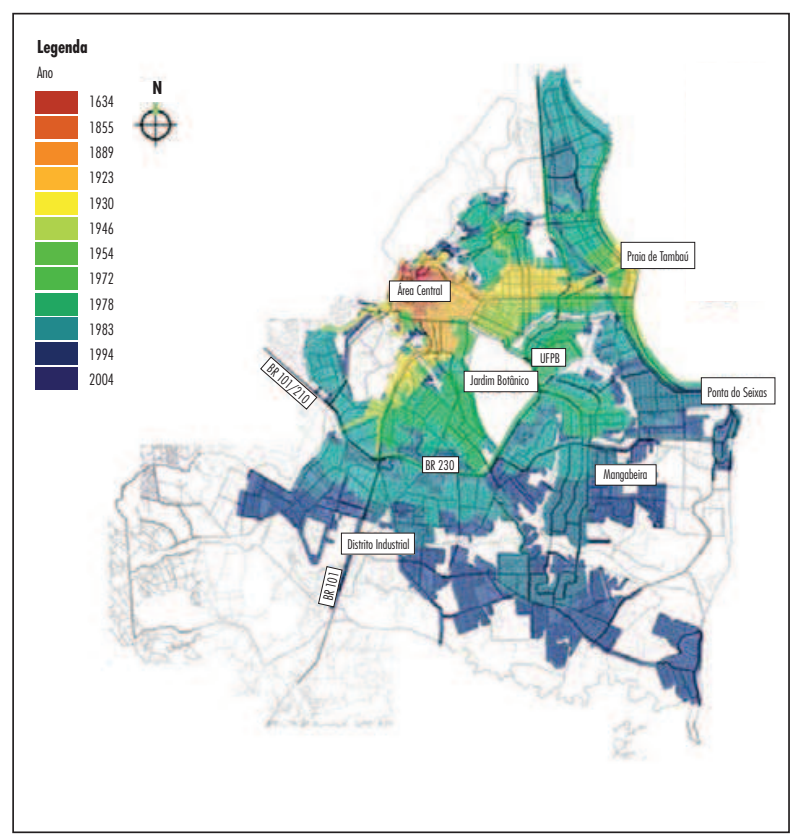

Figura 6 - Reconsitiviçã̃o da área urbana de João Pessoa em diversos períodos, mostrando a sua expansão e dispers̃ão gradativa 
centro da cidade (Figura 7). De acordo com esse modelo, as áreas residenciais de alto status localizam-se no setor de maiores amenidades, cercadas pelos setores de população de médio status. Diametralmente oposto encontra-se um amplo setor habitado pela população de baixo status (SILVEIRA et al., 2008).

Durante o processo de expansão da cidade, os interesses das classes de alta renda ocuparam as áreas elevadas, planas e litorâneas (Setor Centro-Leste, classe de alta renda, e Setor Sudeste, classe média) estimulando nesses locais o surgimento de comércio e de serviços. Esses subcentros, nos bairros de Cabo Branco, Tambaú, Manaíra e Bessa, incentivaram a construção de escolas, mercados, lojas, consultórios, restaurantes, profissionais liberais e demais serviços. No entanto, os setores de classe média-baixa (CentroSul-Sudeste) e de baixa renda (setores Centro-Sul e Oeste) estão situados predominantemente nas áreas com infraestrutura precária, em áreas ambientalmente frágeis (áreas alagadas de Mandacaru, do Rio Jaguaribe, do Bairro São José) e áreas desvalorizadas do centro (ANDRADE et al., 2009).

A expansão urbana em direção à orla marítima ocorreu atrelada à ideia desenvolvimentista, ao valor mercadológico da localização espacial urbana e ao modelo automobilístico-rodoviário, caracterizado pelo dimensionamento das rodovias para o automóvel particular, negligenciando o transporte público e com investimentos insuficientes para promoção da mobilidade da população de baixa renda. Para Oliveira (2006), o intenso processo de modernização demandou intervenções rápidas na estrutura urbana, mudanças no sistema viário e de transportes, que foram concebidas de forma pontual e descontínua. 0 espraiamento da cidade torna cada vez mais difícil a integração entre as áreas com um único meio de transporte quando, seguindo a linha de pensamento da sustentabilidade urbana, deveria estimular a expansão para o interior da malha urbana, ocupando os vazios urbanos.

De acordo com dados operacionais da Superintendência de Transportes e Trânsito de João Pessoa (STTRANS, 2005), o sistema de transportes coletivos da cidade, que já chegou a transportar mais de 10.000 .000 passageiros por mês no início da década de 1990, em 2005 transportava cerca de 8.500.000 passageiros por mês, produzindo quase o dobro de sua quilometragem, com o dobro da frota. Ao contrário de 1993, quando esse sistema

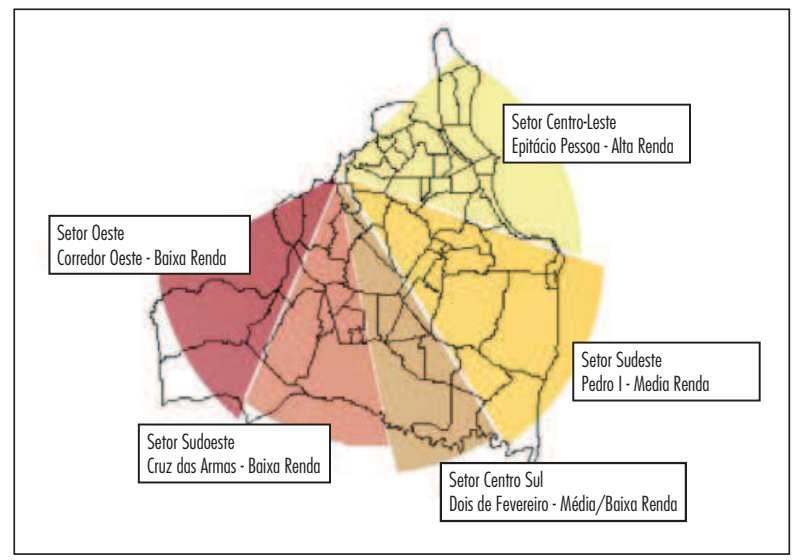

Figura 7 - Esquema estrutural urbano da cidade de João Pessoa pelo modelo de Hoyt

Fonte: OLIVEIRA, 2006.

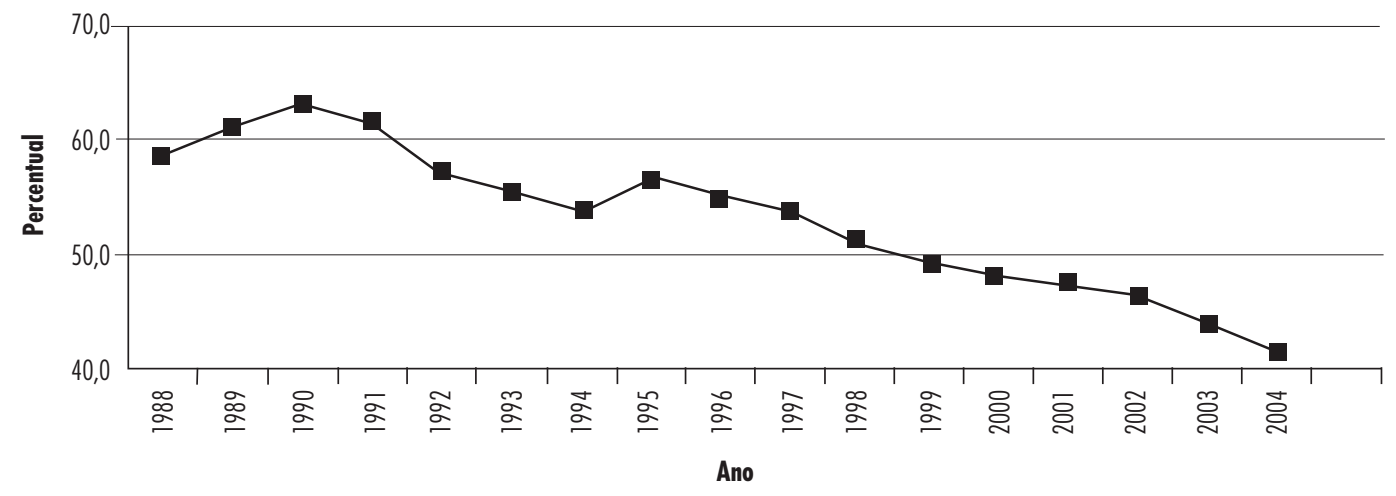

Gráfico 1 - Taxa de percentual de passageiros transportados por dia/População 1988-2004 
transportava em média três passageiros equivalentes a cada quilômetro rodado, em 2005 tinha um índice de 1,86 passageiros por quilômetro percorrido, e com tendência de queda. Algumas linhas radiais operavam com rotas de mais de $50 \mathrm{~km}$ e o índice de passageiros por quilômetro estava abaixo de 0,8 (FREIRE, 2008).

De forma geral, entre 1988 e 2004, o percentual de passageiros transportados por dia, em relação à população, diminuiu. Parte da explicação para essa queda foi direcionada ao aumento da aquisição de automóveis particulares por meio de financiamentos mais acessíveis, e de motocicletas, em virtude do seu baixo consumo de combustível (OLIVEIRA, 2006).

Recentemente, na gestão do Prefeito José Luciano Agra de Oliveira (1998-2012), autor de parte das referências citadas sobre o estudo da evolução urbana de João Pessoa, foram executadas obras na área de transporte, tais como a implantação de proposta da Estação de Integração das linhas de ônibus coletivos, o incentivo ao uso da bicicleta com a construção e extensão de ciclovias e ciclofaixas, e a inserção de um sistema de bicicletas públicas (o "Pedala João Pessoa"), que consiste em quatro estações para locação de bicicletas localizadas na orla da cidade.

Contudo, é o projeto "Caminho Livre" (Figura 8) que está causando mais polêmica. Esse projeto, vinculado ao Programa de Aceleramento do Crescimento (PAC) da Mobilidade Urbana, do Governo Federal, foi divulgado pela Prefeitura Municipal de João Pessoa em julho de 2011, com o objetivo de reordenar o trânsito da cidade por meio, por exemplo, da ampliação das avenidas Epitácio Pessoa e José Américo de Almeida, e da duplicação da via do Altiplano.

Uma das críticas, publicada no site Vitruvius, é de autoria dos cientistas sociais Rodrigo Freire e David Soares (2011). Eles reconhecem a importância do projeto no que tange às diretrizes de ordenamento do trânsito e na ampliação do acesso aos transportes públicos, mas criticam, dentre outros aspectos, o processo de formulação da política pública realizado sem ampla participação da população. De acordo com os autores, durante o processo de elaboração do projeto "Caminho Livre", não foi observado nenhum dos mecanismos de participação previstos na Lei n. 10.257/2001, denominado Estatuto da Cidade, como debates, audiências e

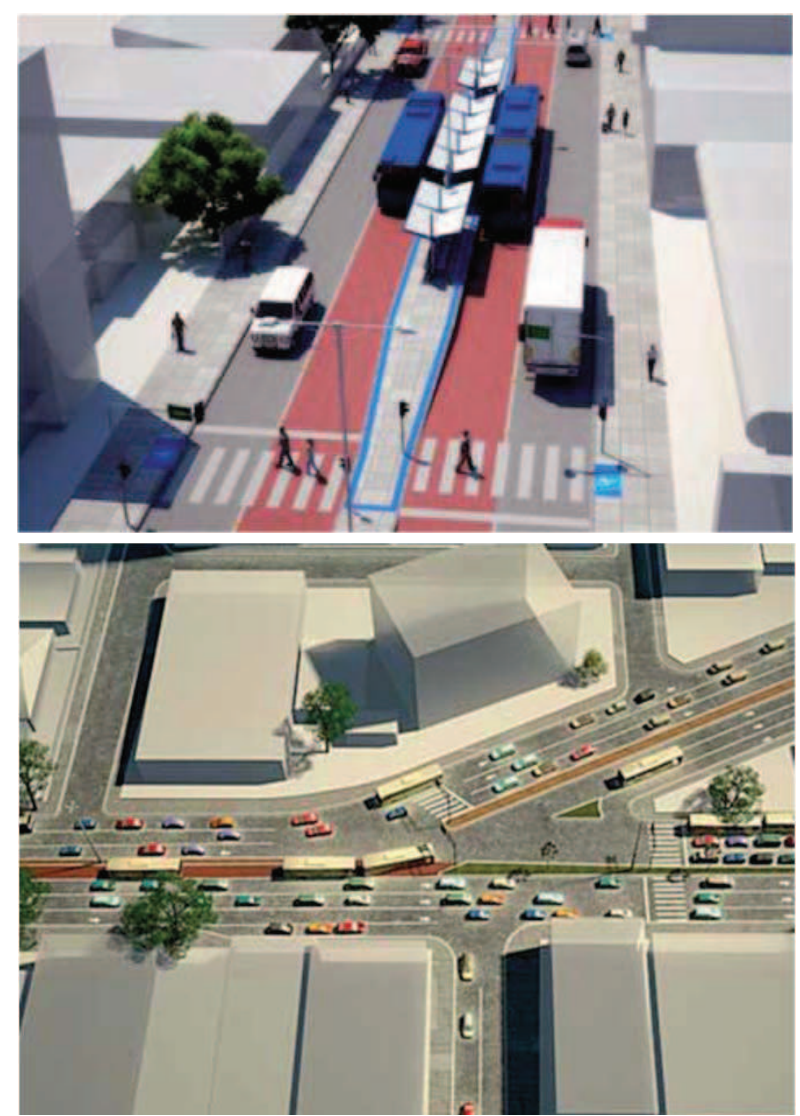

Figura 8 - Imagens gráficas do Projeto "Caminho Livre" Fonte: PREFEITURA DE JOÃO PESSOA, 2011.

consultas públicas. A população não teve garantido o direito de intervir (com sugestões, opiniões, questionamentos), e também não teve amplo acesso aos documentos (dados e detalhes técnicos). Nas palavras dos autores:

[...] tal projeto impactará decisivamente o modo de vida na cidade, afetando a forma de se locomover e - em alguns casos - de se morar em João Pessoa. Sob os termos da gestão democrática e participativa que anuncia o Estatuto da Cidade, isto justificaria o envolvimento popular na formulação do projeto. Em oposto, a Prefeitura de João Pessoa optou por uma política pública tecnocraticamente formulada por meia dúzia dos "iluminados", trancados em gabinetes, desconsiderando que as pessoas que vivem na cidade podem e devem ser percebidas como sujeitos políticos ativos, participativos e capazes de opinar sobre os rumos da cidade onde vivem (FREIRE; SOARES, 2011, p. 4). 
A crítica parece pertinente na medida em que a reflexão diante das alternativas de transporte que impliquem em adotar os princípios da sustentabilidade urbana deve considerar não apenas dados técnicos e estatísticos na seleção de propostas mais adequadas, mas também deve promover a pactuação da sociedade em torno das alternativas de mobilidade urbana, sob pena de se investir recursos vultosos em "soluções" tecnicamente consistentes, mas política e socialmente não legitimadas.

\section{Considerações finais}

Por meio do estudo da evolução urbana de João Pessoa foi possível perceber a atuação de diferentes agentes sociais na dinâmica do fenômeno do sprawl urbano. Tanto o setor público com as intervenções urbanas governamentais (com aberturas de vias e construção de conjuntos habitacionais, por exemplo) quanto a iniciativa privada (setor imobiliário) direcionada aos interesses das classes média e alta, e também a população de baixa renda (excluída do mercado de terras) na ocupação territorial de áreas de proteção ambiental ou non-edificante, atuam diretamente na estruturação da malha urbana.

Parece urgente buscar-se alternativas para neutralizar ou minimizar o impacto dos problemas urbanos em João Pessoa, os quais são decorrentes, dentre outros fatores, da adoção do modelo automobilístico-rodoviário urbano. Os congestionamentos de trânsitos - motos, carros ou ônibus - já demonstram a saturação desse modelo, tanto do ponto de vista da sua estrutura física quanto ambiental. Além disso, verifica-se a influência das formas de expansão urbana, em relação à geração de segregação socioespacial, nos obstáculos à acessibilidade do pedestre em função da estrutura extensiva e direcionada ao automóvel.

É visível o desequilíbrio existente entre as classes sociais, que resultam na segregação social e espacial; as classes mais abastadas são bem assistidas em infraestrutura, embora essas vias de circulação da cidade já apresentem problemas de congestionamentos ocasionados pela crescente frota de veículos particulares. Portanto, se a expansão urbana resulta não apenas de planos e projetos técnicos governamentais, mas também da atuação do setor privado, dos interesses da classe média e alta, e das alternativas de ocupação territorial implantadas pela população de baixa renda, parece provável que as alternativas de deslocamento na cidade (atual) de João Pessoa exigem boas soluções técnicas advindas da administração pública e que se promova o diálogo entre os atores sociais envolvidos.

Se uma possível sustentabilidade urbana deve ser perseguida como meta importante para a adequação de cidades em relação aos problemas contemporâneos, então parece que os atores envolvidos (governos, iniciativa privada, e população) devem se inserir em um processo contínuo e gradativo de mudanças, tanto culturais, sociais, físicas e econômicas, quanto de organização administrativa governamental, de segurança pública, de redistribuição de renda, e de acesso à terra urbana. Dessa maneira, seria possível o surgimento de alternativas de deslocamento adequadas às complexidades e às especificidades históricas, culturais, sociais, políticas e econômicas locais.

\section{Referências}

AGUiAR, W. H. V. Cidade de João Pessoa: a memória do tempo. João Pessoa: Idéia, 2002.

ANDRADE, P. A. F.; RIBEIRO, E. L.; SILVEIRA, J. A. R. Centralidade urbana na cidade de João Pessoa - PB: uma análise dos usos comerciais e de serviços entre o centro tradicional e o centro seletivo - 1970/2006. Vitruvius, v. 9, n. 106, março 2009. Disponível em: <http://www.vitruvius.com.br/revistas/read/arquitextos/ 09.106/69>. Acesso em: 3 mar. 2012.

ASSOCIAÇÃO NACIONAL DE TRANSPORTES PÚBLICOS ANTP. Transporte humano: cidades com qualidade de vida. São Paulo: ANTP, 1997.

CAMPOS FILHO, C. M. Reinvente seu bairro. São Paulo: Editora 34, 2003.

CAMPRECIÓS, J. A cidade em sua dinâmica em direção à sustentabilidade. In: CENTRO IBEROAMERICANO DE DESENVOLVIMENTO ESTRATÉGICO URBANO - CIDEU. Sustentabilidade urbana: contribuição das cidades frente à mudança climática. Barcelona: AECID, 2008.

COUTINHO, M. A. F. Evolução urbana e qualidade de vida: o caso da Avenida Epitácio Pessoa. 2004. 202 f. Dissertação (Mestrado em Desenvolvimento e Meio Ambiente) - Universidade Federal da Paraíba, João Pessoa, 2004. 
CORRÊA, R. L. 0 espaço urbano. 2. ed. São Paulo: Ática, 1993.

FERRAZ, S.; DUAYER, J. Pesquisa, produção e consumo da habitação e o mercado imobiliário em João Pessoa. João Pessoa: Editora Universitária da UFPB, 1985.

FREIRE, P. S. M. O transporte urbano de João Pessoa. Vitruvius, v. 8, n. 92, mar. 2008. Disponível em: <http:// www.vitruvius.com.br/revistas/read/minhacidade/08.092/1898>. Acesso em: 4 mar. 2012.

FREIRE, R.; SOARES, D. A intervenção no trânsito de João Pessoa: caminho fechado para a sustentabilidade e a participação popular. Vitruvius, v. 12, n. 135, out. 2011. Disponível em: <http://www.vitruvius.com.br/revistas/read/minhacidade/12.135/4069>. Acesso em: 4 mar. 2012.

GONÇALVES, R. C. et al. A questão urbana na Paraíba. 3. ed. João Pessoa: Editora Universitária da UFPB, 1999.

JAKOB, A. A. E. Urban sprawl: custos, benefícios e o futuro de um modelo de desenvolvimento do uso da terra. In: ENCONTRO DA ASSOCIAÇÃO BRASILEIRA DE ESTUDOS POPULACIONAIS, 13., 2002, Ouro Preto. Anais... Ouro Preto: ABEP, 2002.

LABORATÓRIO DO AMBIENTE URBANO E EDIFICADO - LAURBE. Reconstituição da área urbana de João Pessoa em diversos períodos, mostrando a sua expansão e dispersão gradativa. João Pessoa: Editora Universitária da UFPB, 2006.

NIJKAMP, P.; RIENSTRA, S. A. Sustainable transport in a compact city. Amsterdam: Amsterdam University Press, 1995.

OJIMA, R. Novos contornos do crescimento urbano brasileiro? O conceito de urban sprawl e os desafios para o planejamento regional e ambiental. GEOgraphia, v. 10, n. 19, p. 46-59, jan./jun. 2008.

OLIVEIRA, J. L. A. Uma contribuição aos estudos sobre a relação transportes e crescimento urbano: o caso de João Pessoa - PB. 2006. 194 f. Dissertação (Programa de Pós-Graduação em Engenharia Urbana) - Universidade Federal da Paraíba, João Pessoa, 2006.

PREFEITURA MUNICIPAL DE JOÃO PESSOA - PMJP. Secretaria de Comunicação. Caminho livre. João Pessoa: PMJP, 2011.

RIBEIRO, E. L. Cidades (in)sustentáveis: reflexões e busca de modelos urbanos de menor entropia. João Pessoa: Editora Universitária da UFPB, 2006.
RIBEIRO, E. L. et al. Controle do sprawl urbano, e inclusão social: o caso da cidade de João Pessoa-PB. In: SIMPÓSIO INTERNACIONAL DE CIÊNCIAS INTEGRADAS, 4., 2007. Anais... Guarujá: UNAERP, 2007. Disponível em: <http://www.unaerp.br/sici/index.php?option=com docman\&task=doc_details\&gid=9\&Itemid=7\&lang=en>. Acesso em: 2 fev. 2012.

RIBEIRO, E. L.; SILVEIRA, J. A. R. O fenômeno do sprawl urbano e a dinâmica da segregação socioespacial. AU, Arquitetura e Urbanismo, n. 185, agosto de 2009. Disponível em: <http://www.revistaau.com.br/arquitetura-urbanismo/185/imprime149628.asp> Acesso em: 2 mar. 2012.

SILVEIRA, J. A. R.; RIBEIRO, E. L.; AMORIM, R. P. L. Percursos, morfologia e sustentabilidade na cidade de João Pessoa PB. Vitruvius, v. 9, n. 98, set. 2008. Disponível em: <http://www.vitruvius.com.br/revistas/read/minhacidade/09.098/1878>. Acesso em: 3 mar. 2012.

SILVEIRA, J. A. R.; RIBEIRO, E. L. Uma abordagem conceitual sobre a acessibilidade urbana. Conceitos, v. 6, p. 171176, 2006.

SALES, A. L. P. 0 centro principal de João Pessoa: espacialidade, historicidade e centralidades. 2009. $141 \mathrm{f}$. Dissertação (Programa de Pós-Graduação em Geografia, Centro de Ciências Exatas e da Natureza) - Universidade Federal da Paraíba, João Pessoa, 2009. Disponível em: <http://www.geociencias.ufpb.br/posgrad/dissertacoes/andrea_sales.pdf>. Acesso em: 3 mar. 2012.

SUPERINTENDÊNCIA DE TRANSPORTES E TRÂNSITO DE JOÃO PESSOA - STTRANS. Relatório de desempenho operacional de transporte coletivo por ônibus. João Pessoa: STTRANS, 2005.

VASCONCELLOS, E. A. Transporte urbano, espaço e equidade: análise das políticas públicas. São Paulo: Annablume, 2001.

VILLAÇA, F. Espaço intra-urbano no Brasil. São Paulo: Studio Nobel, 2001.

Recebido: 23/03/2011

Received: 03/23/ 2011

Aprovado: 16/04/2012

Approved: 04/16/2012 